\title{
Hepatic glycogen levels in female rats submitted to aquatic therapy after muscle disuse
}

\author{
Jefferson Pacheco Amaral Fortes ${ }^{1}$, Felipe Lima de Carvalho ${ }^{1}$, Juliana Osório Alves², Marcia \\ Maria Gonçalves Felinto Chaves ${ }^{1}$, Mayara Rangel Araújo Carneiro ${ }^{3}$, Karla Camila Lima de \\ Souza $^{2}$, Francisco Fleury Uchoa Santos Júnior ${ }^{2,3}$, Vânia Marilande Ceccatto ${ }^{2 *}$
}

\begin{abstract}
The aim of the present study was to analyse the changes in liver glycogen content in rats subjected to aquatic therapy post-disuse of the paw. 32 wistar adult female rats were equally divided: Control (C), kept in the cage for two weeks without interventions; Disuse (D) had the right paw immobilized with hip extension, knee and plantar flexion for two weeks; Aquatic Therapy (AT) underwent aquatic therapy with increments of 3 minutes daily for two weeks, totalizing 36 minutes of training; Disused Aquatic Therapy (DTA) was first subjected to immobilization for two weeks and 24 hours after withdrawal of immobilization aquatic therapy was started for two more weeks, in same protocols of D and AT groups. At the end of the experiment, the animals were sacrificed, and tissues were dissected, weighed and stored. The liver tissues were referred analysis of glycogen content. It was observed that the blood glucose levels of the AT group $(104 \mathrm{mg} / \mathrm{dL})$ were different from the $\mathrm{C}$ group $(86 \mathrm{mg} / \mathrm{dL} ; \mathrm{p}=0.0213)$. Regarding hepatic glycogen, the $\mathrm{D}$ $(2.35 \mathrm{mg} \pm 0.07)$ and AT $(2.73 \mathrm{mg} \pm 0.07)$ groups had hepatic glycogen reduction by $22 \%$ and $15 \%$, relative to $\mathrm{C}(2.51 \mathrm{mg} \pm 0.03) ; \mathrm{p}<0.0001)$. The DTA group presented no differences when compared to the control, suggesting the normalization of the finding. Muscle disuse by two weeks promoted changes in glycogen levels, however, two weeks after disuse condition, the aquatic therapy were able to correct the energetic reserve in liver.

Keywords: Metabolism, Immobilization, Glycogen, Muscle, Liver.
\end{abstract}

\section{INTRODUCTION}

The muscle disuse induced by immobilization of a body segment is widely used in treatment of traumatic injuries, ostheomyoarticular injuries and algic pathologies to assist therapy and promote bone healing. Several biochemical, metabolic and structural changes are found in muscle disuse related to immobilization (Alves et al., 2013; Volpi et al., 2008). Among them is muscle atrophy, a process that causes loss of strength, gradual decreasing of the activities performed by the patient and metabolism changes (Appell, 1990).

Muscle disuse, even for a short period of time, can cause muscle hypotrophy, increased connective tissue, reduction of metabolic activities, among other changes (Bertolini,
Oliveira, \& Cararo, 2010). Regarding the metabolic changes, we highlight the energy metabolism in which glycogen is the main element and its largest reserves are found in the liver and skeletal muscle (Lima-Silva et al., 2007). In the liver, glycogen can be converted to glucose, led into the bloodstream and directed to different tissues, which sharpens the development of studies on mobility loss (Ploug et al., 1995), acting as a source of energy for muscle contraction (Carlos et al., 2014; Motta, 2011).

The glucose acts in the muscle energy metabolism, especially by a GLUT-4 transporter (Hundal et al., 1992) and this could be related with glycogen synthesis. In addition, the glucose blood control is relevant to body functions and it is maintained by glucose intake and glycogen

\footnotetext{
Manuscript received at January $1^{\text {st }}$ 2017; Accepted at May $18^{\text {th }} 2017$

${ }^{1}$ Faculdade de Tecnologia Intensiva, Fortaleza, Brazil

${ }^{2}$ Universidade Estadual do Ceará, Fortaleza, Brazil

${ }^{3}$ Centro Universitário Estácio do Ceará, Fortaleza, Brazil

* Corresponding author: Laboratory of Biochemistry and Genic Expression - Superior Institute of Biomedical Sciences. Av. Dr. Silas Munguba, 1700 - Campus do Itaperi. Fortaleza/CE/Brasil. CEP: 60714-903. Tel.: (+55) 853101 9814; www.uece.br/cmacf E-mail: vania.ceccatto@uece.br
} 
equilibrium between synthesis and consumption (Klip, 1990; Nunes \& Mello, 2009). Moreover, this related glucose process could influence the hepatic and muscle glycogen values (Salway, 2004).

Mobility impairment is usually treated by several physical therapy techniques, among them, the use of aquatic therapy. The aquatic therapy is used to treat rheumatic (Biasoli \& Machado, 2006), neurological (Resende, Rassi, \& Viana, 2008) and vestibular (Gabilan, et al., 2006) disorders and orthopaedic trauma (Pestana et al., 2012). Its physiological effects benefit the tissue repair process, improving peripheral circulation and oxygen supply for muscle tissue, reducing the sensitivity of nerve endings, muscle relaxation and decreased musculoskeletal overload (Pestana et al., 2012; Medeiros et al., 2004). In this context, this present study investigates the liver glycogen content in rats submitted to aquatic therapy after two weeks of paw immobilization, searching for possible changes in this variable. The aquatic therapy is a very popular rehabilitation method, but it is extremely important to verify the possible beneficial changes in body functions and metabolism, which are still unknown. The hypothesis of this research is that aquatic therapy can modulate the glucose/glycogen values, producing recovery in liver glycogen contents post to disuse condition. In this context, this present study aimed to investigate the liver glycogen content in rats submitted to aquatic therapy after two weeks of paw immobilization.

\section{METHODS}

The study had the approval of the Ethics Committee for the Use of Animals of State University of Ceará - Fortaleza/CE - Brazil, registered under the number 10725887-0/18. It was used thirty-two female rats (Rattus norvegicus, Wistar), young adult ( \pm 20 weeks old), average body weight of $200 \pm 15 \mathrm{~g}$. The animals were kept at a temperature of 22 to $25{ }^{\circ} \mathrm{C}$, according to a cycle of 12 hours light/dark, with food and water ad libitum. At the end of the experiment the animals were anesthetized (Ketamine $60 \mathrm{mg} / \mathrm{kg}$ and Xylazine $8 \mathrm{mg} / \mathrm{kg}$ ) and sacrificed for subsequent dissection of parts to be used. Tissues (liver, and the right gastrocnemius, red and white portion) were removed, weighed and stored in nitrogen fluid for subsequent analysis.

\section{Experimental Groups}

The animals were divided into four (4) experimental groups $(n=8), 32$ rats total: Control group (C), at the beginning of the experiment, was separated from the other animals, weighed and left in the cages for two weeks without experimental interventions. Disuse group (D), was maintained under the same conditions as the control group, and the right hind limb was kept immobilized for two weeks. Aquatic Therapy (AT), group underwent the aquatic training protocol for two weeks, starting with 3 minutes per day and daily increments of 3 minutes totalizing 36 minutes on the last day of training. Disuse Aquatic Therapy (DAT), group was maintained under the same conditions as the $\mathrm{D}$ group, the right hind limb was kept immobilized for two weeks. Twenty-four hours after immobilization withdrawal, the animals started the aquatic training for another two weeks, as described in the AT group.

\section{Immobilization Technique}

The immobilization was maintained for two weeks. The right hind limb was immobilized with waterproof tape $\left(\mathrm{Cremer}^{\circledR}\right.$ tape, $10 \mathrm{~cm}$ wide), involving the pelvis, hip and knee in extension and the ankle in plantar flexion. Immobilization did not prevent the animals from moving or eating (Santos Júnior et al., 2010).

\section{Aquatic Therapy}

To perform the aquatic therapy, the animals swam in a plastic (PVC) container filled with approximately 60 liters of water. The adapted therapeutic protocol (Gomes et al., 2016) started with 3 minutes a day followed by daily increase of 3 minutes until reaching 36 minutes at the end of the second week. A resistance was applied in the tail of the animal, corresponding to $5 \%$ of its body weight in order to avoid the fluctuation during the aquatic therapy. The exercises in the water were performed in the morning, during six days a week followed by a weekly rest on Sunday. The water temperature was maintained at $33 \pm 1^{\circ} \mathrm{C}$, 
measured by a thermostat. The animals were then immediately dried using a hot air flow device.

\section{Glycemia}

Glucose levels were analysed using the Accucheck ACTIVE $^{\circledR}$ (Roche), a blood glucose monitoring system. The rats were fasted for a period of $8 \mathrm{~h}$.

\section{Evaluation of glycogen content}

The liver tissue $(200 \mathrm{mg})$ was digested in $30 \%$ $\mathrm{KOH}$ solution, boiled for 30 minutes, and the glycogen evaluation was based on the phenol sulfuric method, read in a spectrophotometer (490 nm) (Lo, Russel, \& Taylor, 1970).

\section{Statistical analysis}

The normality was checked using the ShapiroWill test and parametric analysis were performed. The results were analysed using the ANOVA test followed by the Kruskal-Wallis test. GraphPad Prism software version 7.00 for Windows was used (GraphPad Software, La Jolla, California, USA). In addition, the Pearson correlation test was performed. Statistical significance was set at $p<0.05$.

\section{RESULTS}

The morphological and functional parameters were analysed among the four groups and the results obtained indicated a weight reduction of the $\mathrm{D}$ group, which include body weight, liver weight, total gastrocnemius weight and white portion of the gastrocnemius comparing to the $\mathrm{C}$ group and AT group. The disuse group showed lower liver and body weight in comparison to DAT group. The DAT group compared to the C, only decreased the weight of total and white portion of the gastrocnemius (Table 1).

Table 1

Morphological and functional parameters of the analysed groups

\begin{tabular}{lcccc}
\hline & C & D & AT & DAT \\
\hline Body weight (g) & $194.8 \pm 2.67$ & $163.7 \pm 3.62^{* \mathscr{}}$ & $194.0 \pm 2,69^{\#}$ & $194.3 \pm 2.82^{\#}$ \\
Liver (g) & $7.835 \pm 0.33$ & $6,271 \pm 0.41^{* \Psi}$ & $7.759 \pm 0.45^{\#}$ & $8.289 \pm 0.31^{\#}$ \\
Gastrocnemius (Total) (g) & $1.193 \pm 0,03$ & $0.712 \pm 0,05^{* \varepsilon}$ & $0.896 \pm 0.12^{\#}$ & $1.083 \pm 0.04^{*}$ \\
White Gastrocnemius (g) & $0.671 \pm 0.04$ & $0.278 \pm 0.03^{* \varepsilon}$ & $0.532 \pm 0.04^{\#}$ & $0.452 \pm 0.06^{*}$ \\
Red Gastrocnemius (g) & $0.441 \pm 0.03$ & $0.370 \pm 0.03$ & $0.447 \pm 0.01$ & $0.437 \pm 0.02$ \\
\hline
\end{tabular}

Values expressed as mean \pm standard error of the mean. $\mathrm{C}=$ Control; D = Disuse; AT = Aquatic Therapy; DAT = Disuse and Aquatic Therapy. ${ }^{*} \mathrm{p}<0.05$ versus $\mathrm{C}$; \# $\mathrm{p}<0.05$ vs. $\mathrm{D}$; $£ \mathrm{p}<0.05$ versus AT; $¥ \mathrm{p}<0.05$ versus $\mathrm{D}$ with AT.

Blood glucose levels were equal in the $\mathrm{C}$ group $(86 \mathrm{mg} / \mathrm{dL}) ; \mathrm{D}(96 \mathrm{mg} / \mathrm{dL})$ and DAT $(94 \mathrm{mg} / \mathrm{dL})$, however, the AT group $(104 \mathrm{mg} / \mathrm{dL})$ was statistically different $(p=0.0213)$ from the $C$ group (Figure 1A).

Regarding the values of liver glycogen (Figure $1 B$ ), it was found $3.22 \pm 0.08 \mathrm{mg}$ in the $\mathrm{C}$ group, $2.51 \pm 0.03 \mathrm{mg}$ in the D group, $2.35 \pm 0.07 \mathrm{mg}$ in the AT group, $2.73 \mathrm{mg} \pm 0.07$ in the DAT group. Groups D and AT were statistically different from the $\mathrm{C}$ group $(p<0.0001)$.

A correlation analysis was performed between hepatic glycogen and blood glucose of the animals (Figure 2) and it was obtained a moderate and inverse correlation ( $p=0,0038 ; r=0,5123)$.

Blood glucose showed a moderated inverse correlation $(r=-0.5123, p=0.0038)$.
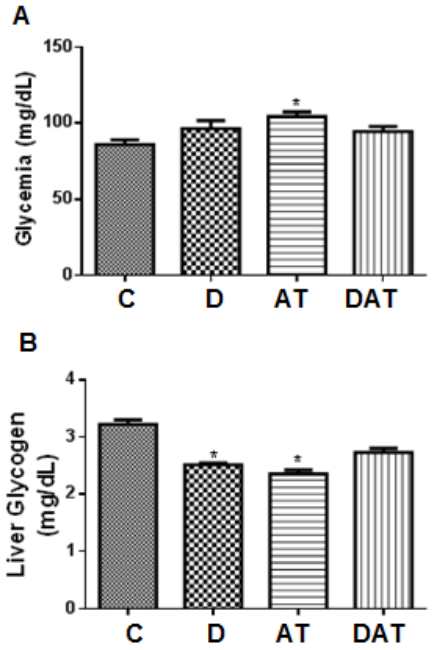

Figure 1. Analysis of serum glucose content and liver glycogen. A - Animal blood glucose levels; B - liver glycogen content in rats. Values expressed as mean \pm standard error of the mean. $\mathrm{C}=$ Control; $\mathrm{D}=$ Disuse; $\mathrm{AT}=$ Aquatic Therapy; DAT $=$ Disuse and Aquatic Therapy. Kruskal-Wallis test; * Statistically different from control; $\mathrm{p}<0.05$. 


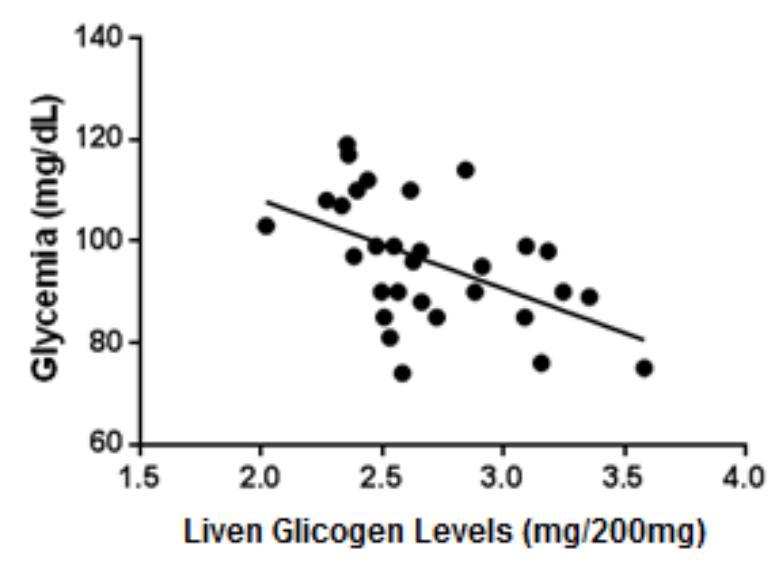

Figure 2. Correlation between blood glucose on the day of sacrifice and liver glycogen.

\section{DISCUSSION}

The present study showed that two weeks of immobilization of a body part caused muscle loss and dysfunction in the energy metabolism reserve. The liver glycogen reserves of D and AT groups were reduced. The performance of the aquatic therapy after immobilization resulted in regain of muscle weight, blood glucose and levels of liver glycogen.

Regarding tissue mass loss, this study demonstrated that two weeks of disuse by paw immobilization in extension caused a decrease in muscle mass of the gastrocnemius, comparing to the $\mathrm{C}$ group, which it was evidenced by the reduction in body and muscle weight. These data are consistent with previous studies, showing that a short period of disuse by immobilization generates weight reduction (Carvalho et al., 2014; Santos Júnior et al., 2010), reduction in muscle length (Carvalho et al., 2014) and contractile capacity (Santos Júnior et al., 2015). It is known that disuse by immobilization promotes several morphological and physiological changes (Alves et al., 2013) and it acts directly in the muscle tone loss, leading to muscle atrophy (Santos Júnior et al., 2010). Two weeks of immobilization can cause loss of myofibrils and decrease of the size of muscle fibers (Ploug et al., 1995), changes in the morphology of the fibers and muscle mechanics (Lima et al., 2007). Skeletal muscles can be affected by external influences, such as therapeutic immobilization, which changes their biochemical and structural characteristics (Artifon et al., 2012). In a previous study on energy metabolism in muscle atrophy (Stein \& Wade, 2005) results showed an increase in enzyme expression values related to gluconeogenesis in the liver, indicating a higher consumption of liver glycogen, which supports the data obtained in this study, considering that a decrease in liver glycogen in immobilized animals was also observed.

The AT group had lower levels of liver glycogen and higher blood glucose compared to the $\mathrm{C}$ group. A previous study about acute intermittent jumping exercise in rats showed an increase in glucose levels and decreased hepatic glycogen levels (Romijn et al., 1993), corroborating with the data obtained in this study. Blood glucose control is essential to the functions of glucose dependent tissues, maintained through consumption of carbohydrates, glycogenolysis and gluconeogenesis (Alves et al., 2013). Exercise increases the oxidation of muscle glycogen (Rogatto et al., 2004), and the reduction of liver glycogen evidenced in this study may be related to higher consumption of muscle glycogen during exercise or as a replacement strategy for muscle glycogen. This fact would justify the lower level of glycogen in the liver and increased glucose circulating in AT group, as supported by statistical correlation.

Aquatic therapy is a resource used in rehabilitation aimed at muscle recovery (Santos Júnior, 2012), in order to provide functional restoration (Canderolo \& Caromano, 2007). Aquatic therapy can promote improvements in muscle strength, flexibility and cardiorespiratory fitness, being efficient in fitness with a less risk of injury (Canderolo \& Caromano, 2007; Canderolo, Caromano, 2008). The DAT group showed values for liver glycogen similar to the $\mathrm{C}$ group, demonstrating that aquatic therapy was effective to restore liver energy reserves.

In a human study, the glycogen contents and the glycogen synthase protein levels were decreased post two weeks of immobilization in the vastus lateralis muscle, and the values were recovered after six weeks of supervised ergometer bicycle training (Vigelso et al., 2016). Our animal model presented similar results in liver and muscle weights, demonstrating that it is possible 
to perform the glycogen liver recovery with aquatic therapy.

\section{CONCLUSION}

The results indicated that the disuse caused by paw immobilization in rats for a two weeks' period promoted significant changes in the hepatic glucose reserves and the aquatic therapy restored some adverse factors of the immobilization, especially influencing the regulation of energy metabolism.

Acknowledgments:

Nothing to declare

\section{Conflict of interest:}

Nothing to declare

\section{Funding:}

Nothing to declare

\section{REFERENCES}

Alves, J. S., Leal-Cardoso, J. H., Santos Júnior, F. F. U., Carlos, P. S., Silva, R. C., Lucci, C.M., ... Ceccatto, V. M. (2013). Limb immobilization alters functional electrophysiological parameters of sciatic nerve. Brazilian Journal of Medical and Biological Research, 46(8), 715-721. doi: 10.1590/1414-431X20132626

Appell, H. J. (1990). Muscular atrophy following immobilization. A review. Sports Medicine, 10(1), 42-58.

Artifon, E. L., Ferrari, D., Cunha, D. M., Nascimento, C. M., Ribeiro, L. F., \& Bertolini, G. R. (2012). Effects of therapeutic ultrasound associated with static stretching on longitudinal histomorphometric parameters of immobilized soleus of rats. Revista Brasileira de Medicina do Esporte, 18(5), 341-344. doi: 10.1590/S151786922012000500012

Bertolini, S. M., De Oliveira, P. D., \& Cararo, D. C. (2010). Morphometric study of post-joint immobilization of soleus muscle on wistar lineage rats. Acta Scientiarum. Health Sciences, 32 (1), 23-27. doi: 10.4025/actascihealthsci.v32i1.5908

Biasoli, M. C., \& Machado, C. M. (2006). Hidroterapia: técnicas e aplicabilidades nas disfunções reumatológicas. Temas de Reumatologia Clínica, 7(3), 78-87.

Candeloro, J. M., \& Caromano, F. A. (2007). Effects of a hydrotherapy program on flexibility and muscular strength in elderly women. Revista Brasileira de Fisioterapia, 11(4), 303-309. doi: 10.1590/S1413-35552007000400010
Candeloro, J. M., \& Caromano, F. A. (2008). Effects of a hydrotherapy program on blood pressure and heart rate in elderly, sedentary women. Fisioterapia e Pesquisa, 15(1), 26-32. doi: 10.1590/S1809-29502008000100005

Carvalho, M. M., Martins, W. R., Blackzick, J. C., Cruz Júnior, C. A., Souza, H. A., Kückelhaus, S. A. S., \& Mota, M. R. (2014). Morphometric analysis of the effects of immobilization on the gastrocnemius muscle of rats. Universitas: Ciências da Saúde, 11(2), 99-106. doi: 10.5102/ucs.v11i2.2518

Carlos, C. S., Oliveira, V. F., Saraiva, L. G., Dornelas, P. G., Corrêa, J. A., Costa, A. M., ... Calábria, L. K. (2014). Glycogenoses: An Overeview. Bioscience Journal, 30(5), 1598-1605.

Gabilan, Y. P., Perracini, M. R., Munhoz, M. S., \& Ganança, F. F. (2006). Aquatic physiotherapy for vestibular rehabilitation. Acta Otorrinolaringologia, 24(1), 23-8.

Gomes, N. M. A., Souza, K. C. L., Rabelo, M., Fortes, J. P. A., Barbosa, L. S., Craveiro, R. M. C. B., Filho, F. S. L. V., Júnior, F. F. U. S., \& Ceccatto, V. M. (2016). Aquatic therapy in bone mineral density in rats after paw disuse by immobilization. International Journal of Therapies \& Rehabilitation Research, 5(5), 161-169. doi: 10.5455/ijtrr.000000200

Hundal, H. S., Ramlal, T., Reyes, R., Leiter, L. A., \& Klip, A. (1992). Cellular mechanism of metformin action involves glucose transporter translocation from an intracellular pool to the plasma membrane in L6 muscle cells. Endocrinology, 131(3), 1165-1173. doi: 10.1210/endo.131.3.1505458

Klip, A., \& Pâquet, M. R. (1990). Glucose transport and glucose transporters in muscle and their metabolic regulation. Diabetes Care, 13(3), 228243.

Lima-Silva, A. E., Fernandes, T. C., Oliveira, F. R., Nakamura, F. Y., \& Gevaerd, M. D. (2007). Muscle glycogen metabolism during exercise: mechanism of regulation. Revista de Nutrição, 20(4), 417-429. doi: 10.1590/S141552732007000400009

Lima, S. C., Caierão, Q. M., Durigan, J. L., Schwarzenbeck, A., Silva, C. A., Minamoto, V. B., \& Guirro, R. R. (2007). Short-term immobilization causes morphometric and mechanical alterations on rat muscles. Revista Brasileira de Fisioterapia, 11(4), 297-302. doi: 10.1590/S1413-35552007000400009

Lo, S., Russel, J. C., \& Taylor, A. (1970). Determination of glycogen in small tissue samples. Journal of Applied Physiology, 28(2), 234236.

Medeiros, A., Oliveira, E. M., Gianolla, R., Casarini, D. E., Negrão, C. E., \& Brum, P. C. (2004). Swimming training increases cardiac vagal activity and induces cardiac hypertrophy in rats. Brazilian Journal of Medical and Biological Research, 
$\mathbf{5 8}$ | JPA Fortes, FL Carvalho, JO Alves, et al.

$37(12), \quad 1909-17 . \quad$ doi: $10.1590 /$ S0100879X2004001200018

Motta, V. T. (2011). Bioquímica (2 ${ }^{\mathrm{a}}$ ed.). Belgium: Medbook.

Nunes, W. M. S., \& Mello, M. A. R. (2009). Glicidic metabolism in rats submitted to denervation of skeletal muscle and swimming exercise. Revista Brasileira de Medicina do Esporte, 15(1), 42-45. doi: 10.1590/S1517-86922009000100009

Pestana, P. R., Alves, A. N., Fernandes, K. P., Silva Júnior, J. A., França, C. M., Martins, M. D., Bussadori, S.K., \& Mesquita-Ferrari, R. A. (2012). Swimming influence on the expression of myogenic regulatory factors during skeletal muscle repair of rats. Revista Brasileira de Medicina do Esporte, 18(6), 419-422. doi: 10.1590/S151786922012000600015

Ploug, T., Ohkuwa, T. E., Handberg, A. A., Vissing, J. O., \& Galbo, H. (1995). Effect of immobilization on glucose transport and glucose transporter expression in rat skeletal muscle. American Journal of Physiology Endocrinology and Metabolism, 268(5), E980-E986

Resende, S. M., Rassi, C. M., \& Viana, F. P. (2008). Effects of hydrotherapy in balance and prevention of falls among elderly women. Revista Brasileira de Fisioterapia, 12(1), 57-63. doi: 10.1590/S141335552008000100011

Rogatto, G. P., Oliveira, C. A. M., Faria, M. C., \& Luciano, E. (2004). Acute metabolic responses of Wistar rats to intermittent jump exercise. Motriz, 10(2), 61-66.

Romijn, J. A., Coyle, E. F., Sidossis, L. S., Gastaldelli, A., Horowitz, J. F., Endert, E., \& Wolfe, R. R. (1993). Regulation of endogenous fat and carbohydrate metabolism in relation to exercise intensity and duration. American Journal of Physiology, 265(3), E380-E391.
Santos Júnior, F. F. U., Alves, J. S., Machado, A. A., Carlos, P. S., Ferraz, A. S., Barbosa, R., LealCardoso, J. H., \& Ceccatto, V. M. (2010). Morphometric alterations in respiratory muscle of rats submitted to paw immobilization. Revista Brasileira de Medicina do Esporte, 16(3), 215-218. doi: 10.1590/S1517-86922010000300012

Santos Júnior, F. F. U., Souza, A. L., Franco, F. G., André, N. M., \& Ceccatto, V. M. (2012). Diaphragmatic rehabilitation postimmobilization with aquatic therapy in rats. Fisioterapia Brasil, 13(6), 420-424

Santos Júnior, F. F. U., Freitas Pires, A., Ribeiro, N. M., Mendonça, V. A., Alves, J. O., Soares, P. M., Ceccatto, V. M., \& Assreuy, A. M. (2015). Sensorial, structural and functional response of rats subjected to hindlimb immobilization. Life Sciences, 137, 158-63. doi: 10.1016/j.lfs.2015.07.020

Stein, T. P., \& Wade, C. E. (2005). Metabolic consequences of muscle disuse atrophy. The Journal of Nutrition, 135(7), 1824S-1828S.

Vigelsø, A., Gram, M., Wiuff, C., Hansen, C. N., Prats, C., Dela, F., \& Helge, J. W. (2016). Effects of immobilization and aerobic training on proteins related to intramuscular substrate storage and metabolism in young and older men. European journal of applied physiology, 116(3), 481-494. doi: 10.1007/s00421-015-3302-x

Volpi, F. S., Casarolli, L. M., Pudell, C., Menon, T., Ciena, A. P., Alves, E. P., \& Bertolini, G. R. F. (2008). Effects of remobilization in two weeks of swimming on the soleus muscle of rats submitted to immobilization. Revista Brasileira de Medicina do Esporte, 14(3), 168-170. doi: 10.1590/S151786922008000300001 